\title{
A HISTÓRIA DA CONSTRUÇÃO IDENTITÁRIA DE PROFESSORES DO ENSINO SUPERIOR
}

Ilda Estela Amaral de Oliveira

Sônia de Jesus Nunes Bertolo

Joyce Viviane da Silva Mescouto

Alga Cristi Vital Vilhena

Universidade Federal do Pará - UFPA

iestela@ufpa.br

\section{RESUMO}

O texto resulta da pesquisa "Por que me fiz professor: narrativas de docentes do ensino superior sobre a construção da identidade profissional' sob a responsabilidade de um grupo de professores e alunos do Instituto de Ciências da Educação (ICED) da UFPA,cujo tema está centrado na construção identitária de professores (12) ao longo de sua vida como docentes no ensino público superior. É um trabalho que teve a intenção de potencializar as vozes cotidianas, as histórias anônimas de professores aposentados. O marco teórico metodológico centra-se no enfoque autobiográfico narrativo da identidade que se (re)presenta e se constitui mediante os relatos de vida que fazem os sujeitos. Trabalhamos com a descrição e análise de cada caso com identidade própria (análise vertical e diacrónica) e em uma perspectiva transversal (horizontal e sincrônica). Adotamos procedimentos de análise de conteúdo. As conclusões a que chegamos são as de que, em seus tempos, historicamente diferenciados, existe uma sintonia no esforço cotidiano para nos tornarmos professores.

Palavras-Chave: histórias de professores; identidades; narrativas autobiográficas

\section{A HISTORY OF IDENTITY CONSTRUCTION OF TEACHER OF HIGHER EDUCATION}

\begin{abstract}
The text search results from "Why I became a teacher: narratives of teachers in higher education on the construction of professional identity' under the responsibility of a group of teachers and students of the Institute of Education(ICED), UFPA, whose theme is centered on the construction of teacher identity(12)throughout his life as teachers in public higher education. It is a work that was intended to empower the voices everyday, anonymous stories of retired teachers. The theoretical methodological approach focuses on the autobiographical narrative of identity that(re) present and that is through the stories of life that make the subjects. We work with a description and analysis of each case with its own identity (vertical analysis and diachronic) perspective and in a transverse (horizontal and synchronic). We have adopted procedures for content analysis. The conclusions reached are that, in their times, historically differentiated, there is a line in the daily effort to become teachers.
\end{abstract}

Keywords: teacherstories; identities; autobiographical narratives 


\title{
CONSIDERAÇÕES INCIAIS
}

\begin{abstract}
Somente quem soubesse considerar o próprio passado como fruto de coação e da necessidade seria capaz de fazê-lo em cada presente, valioso ao máximo para si. Pois aquilo que alguém viveu é, no melhor dos casos, comparável à bela figura à qual, em transportes, foram quebrados todos os membros, e que agora nada mais oferece a não ser o bloco precioso a partir do qual ele tem de esculpir a imagem de seu futuro. (WALTER BENJAMIM)
\end{abstract}

Este é um trabalho vinculado ao projeto de pesquisa "Por que me fiz professor: narrativas de docentes do ensino superior sobre a construção da identidade profissional" aprovado institucionalmente pelo Instituto de Ciências da Educação (ICED) da Universidade Federal do Pará (UFPA). O tema está centrado na construção identitária de professores ao longo de sua vida como docentes no ensino público superior. Contamos com a participação de 12 professores aposentados do ICED.

$\mathrm{Na}$ construção de nossa proposta partimos do pressuposto de que o homem é essencialmente um contador de histórias. No contar histórias os seres humanos corporificam idéias, crenças e valores que se entrelaçam nas narrativas.

Contar histórias é não apenas a demonstração de um saber, mas a realização de um saber: quem conta histórias organiza o mundo, dá-lhe sentido, comunica-o, de forma que, pelo confronto com o mundo, que está fora ou para além da história, este é transformado, ganhando novos sentidos e interpretações. (SARMENTO, 1994, p. 123)

No entanto, a evocação da natureza humana não basta para que este ato possa ser configurado como via adequada de aquisição de conhecimento científico. Contar histórias não se constitui apenas na demonstração de um saber, mas a realização de um fazer. A história de cada indivíduo e o seu bem mais preciso, o seu maior patrimônio. Daí, porque não pode ser esquecida. Ela precisa ser lembrada, conhecida, reverenciada e (re)transmitida ao longo do tempo.

A memória entra nessa dinâmica como a grande "revitalizadora" do existir. O voltar à memória não significa estabelecer uma rigidez entre passado, presente e futuro. Memória e tempo estão intimamente ligados e podem ser analisados através do resgate da história.

Fazer história é, portanto, ser capaz de explicitar o diálogo interminável entre presente, passado e com as propostas, expectativas e discursos futuristas. Neste diálogo o sujeito e o fato adquirem facetas múltiplas sempre que entram em relacionamento. O jogo de relações que se constrói nessa dinâmica é sempre produto das circunstâncias e, em virtude disto, pode ser olhado sob diferentes ângulos.

Desta forma, o olhar do homem no tempo e através do tempo revela uma forte marca de historicidade. São os homens que constroem sua visão e representação das diferentes temporalidades e acontecimentos. Quando nos dedicamos à análise do passado, vamos ao encontro de um outro tempo, com suas singularidades. Como declara Neves (1999, p. 1) "cada tempo tem seu substrato e cada substrato temporal inclui em si singularidade e multiplicidade". 
E é isto que aqui se põe em questão, quando nos propomos a ter acesso à construção cultural e simbólica de professores aposentados, mediante histórias contadas por eles. Este esforço por ouvir a voz e por dar voz a esses professores, significa o reconhecimento de que essas trajetórias têm significados importantíssimos na construção da identidade docente no ensino superior.

Entendemos que as histórias pessoais de docentes que viveram sua trajetória profissional numa universidade pública trazem consigo o ambiente universitário e sua história de construção coletiva. Entender a história desses docentes é entender a própria história da educação superior no Estado do Pará, mediante seus percursos, movimentos, reivindicações, propostas e projetos de política educacional.

A realização da presente pesquisa constituiU-se, principalmente, num tributo a todos aqueles que um dia viveram "O Centro de Educação", hoje Instituto de Ciências da Educação (ICED).

Mas por que registrar essas histórias? Queremos deixar um documento que traduza todo um caminhar de professores que, em suas épocas, marcaram a docência em suas múltiplas dimensões. Como educadores contribuíram, de forma significativa, para a construção de saberes relativos à formação de futuras gerações. É preciso dar-lhes vez e voz. A reflexão sobre suas representações poderão significar um passo importante para nos revermos como profissionais da educação, repensarmos nossas próprias práticas e a forma como estamos construindo nossa própria identidade profissional.

Entendemos que ao possibilitar as narrativas desses professores estaremos resgatando a história do ICED por intermédio de seus protagonistas, pois pelas narrativas damos sentido e significado ao que somos, ao que fomos e ao que podemos ser.

\section{O TEMA PROBLEMATIZADO}

A educação é um processo que possibilita aos seres humanos inserirem-se na sociedade, historicamente construída e em constante movimento de construção. Sua tarefa é garantir que instrumental científico, técnico, tecnológico, de pensamento, político, social e econômico e de desenvolvimento cultural seja apropriado de forma reflexiva e crítica. Se por um lado retrata e reproduz a sociedade, por outro lado projeta a sociedade que se almeja. É nessa contradição que estão inseridas as demandas por educação.

Neste contexto, faz-se presente a figura do professor, inserido num processo mediador entre sujeitos (alunos) para a conquista do conhecimento. A docência constitui-se, assim, num campo específico da intervenção profissional no campo social. Na universidade configura-se como um processo contínuo de construção da identidade, mediante trabalho com os saberes de sua área específica.

Essa construção dá-se desde a fase inicial de sua formação e pelas oportunidades acadêmicas que vão surgindo já no exercício da profissão pelo convívio com outros profissionais, pela continuidade dos estudos e nas relações entre teoria e prática.

Como profissão, a docência configura-se como uma atividade necessária, sustentada por bases teóricas, práticas e éticas. É preciso reconhecer nesta profissão sua especificidade epistemológica "que resgata a utopia e a ideologia que se manifestam na intencionalidade" (CUNHA, 1998, p. 145).

Partimos do pressuposto de que os professores são profissionais que contribuem, significativamente, com seus saberes, seus valores e suas experiências na ampla tarefa de melhorar a qualidade social da escolarização. Como profissionais, sua formação identitária é epistemológica, reconhecendo a docência dentro de um específico campo do 
conhecimento. Que conhecimentos são esses? O que os distingue dos demais profissionais? $\mathrm{O}$ que o identifica como professor?

A profissão de professor situa-se num determinado contexto e momento histórico e pode assumir características diferenciadas. O caráter dinâmico da profissão permite-nos analisar o próprio movimento de construção. E é na leitura crítica deste movimento que fundamentamos a presente pesquisa.

Uma identidade profissional se constrói, pois com base na significação social da profissão; na revisão constante dos significados sociais da profissão; na revisão das tradições. Mas também com base na reafirmação de práticas consagradas culturalmente que permanecem significativas. (PIMENTA e ANASTASIOU, 2002, p.77).

A identidade profissional é também construída pelos significados que cada professor confere à docência, considerando os seus valores, seu modo de situar-se no mundo, suas representações, suas angústias e seus anseios. Neste processo, sobressai-se como fundamental o significado social que os professores conferem ao seu trabalho.

Para Nóvoa (1992) para a construção da identidade docente são essenciais três processos: o desenvolvimento pessoal, que se refere aos processos de produção da vida do professor; o desenvolvimento profissional, que se refere aos aspectos da profissionalização docente; e o desenvolvimento institucional, que se refere aos investimentos da instituição para o alcance de seus objetivos. Os processos de profissionalização continuada inserem-se neste tríplice investimento.

Partindo do pressuposto de que a docência é um campo específico de intervenção na prática social, a docência no ensino superior possui características peculiares, não distanciadas da identidade básica. É fundamental, pois nesta pesquisa tratar da construção da identidade do docente, a formação, as experiências vivenciadas com seus sucessos, desafios e insucessos e os significados atribuídos a essas vivências. É intenção pesquisar a prática como espaço de apropriação de uma competência diferenciada, para discuti-la e analisá-la.

Também trataremos do processo de formação (inicial e continuada), considerandose a importância dos saberes das áreas específicas do conhecimento e dos saberes didáticos que tratam da articulação de diferentes teorias para ensinar e dos saberes da experiência do sujeito - como nos apropriamos do ser professor no decorrer de nossas vidas (PIMENTA e ANASTASIOU, 2002).

Goodson (1992) instiga-nos a uma reflexão para compreender que os estudos referentes à vida de professores podem ajudar-nos a ver o indivíduo situado na sua história e no seu tempo, possibilitando perceber a intersecção da história de vida com a história da sociedade, revelando as escolhas, contingências e opções assumidas por cada um. Trata-se, desta forma de resgatar a riqueza e a importância das recordações dos sujeitos, possibilitando às pessoas que fizeram a história um lugar especial mediado por suas próprias narrativas. Ao rememorar suas vivências o façam com a dignidade de quem tem muito ainda a contribuir com as novas gerações.

Thompson (2002) declara que a história oral está hoje consolidada em vários países, percebendo o uso da entrevista narrativa como um instrumento precioso para o resgate da memória dos sujeitos. Ainda é Thompson que nos diz que uma das primeiras experiências com história oral no Brasil ocorreu em 1971, em São Paulo, no Museu da Imagem e do Som, dedicado à preservação da memória cultural brasileira. Outras experiências vem sendo consolidadas em diferentes instituições do ensino superior. A exemplo,cita o Centro de Pesquisas e Documentação de História Contemporânea do Brasil, na Fundação Getúlio 
Vargas, que vem desde 1975 dispondo de um amplo acervo, contando com entrevistas com personagens da história política contemporânea.

O relato de histórias permite o acúmulo de novas versões dos acontecimentos ao dar voz aos narradores. Permite construir a história a partir das vozes dos próprios sujeitos, daqueles que vivenciaram um determinado período de suas vidas, através de suas referências e de seu imaginário. $\mathrm{O}$ registro de cada reminiscência faz de cada um uma personagem histórica.

Partindo dessa perspectiva, justificamos esta pesquisa como uma das possibilidades plausíveis de resgatar a construção da identidade docente, via narrativas de professores universitários aposentados, buscando evidências de questões relacionadas à formação, percurso, experiências, crenças e valores manifestas pelos relatos.

\section{SINALIZAÇÕES SOBRE O TEMA}

No atual cenário, de transformações aceleradas, inúmeras questões põem-se frente a nós quando centramos nosso olhar sobre a docência no ensino superior: qual é o real papel do professor diante das crescentes demandas sociais, diante da explosão do conhecimento e da informação? O que identifica um professor universitário? Não temos respostas conclusivas. Temos diante de nós uma temática impregnada de dúvidas e incertezas.

Cremos que a educação é um processo que possibilita aos seres humanos inseriremse na sociedade, historicamente construída e em constante movimento de construção. Sua tarefa é garantir que instrumental científico, técnico, tecnológico, de pensamento, político, social e econômico e de desenvolvimento cultural seja apropriado de forma reflexiva e crítica. Se por um lado retrata e reproduz a sociedade, por outro lado projeta a sociedade que se almeja. É nessa contradição que estão inseridas as demandas por educação.

É o caso de dizermos que o conhecimento e técnica devem estar estreitamente articulados com a ética, com vistas à construção de uma sociedade mais inclusiva, gerando menos desigualdades, num processo mais justo, mais solidário e emancipatório. Então a educação superior assume um papel de extrema relevância social. Como declara Pimenta (2009, p. 25)

Não basta apenas acumular conhecimentos. Isso pode até ser inútil, pois muitos deles possivelmente estarão superados em curto espaço de tempo. É necessário conhecer mais e mais, porém é fundamental e primordial a formação ética, pela qual a construção, a socialização e os usos da ciência e da técnica, sejam colocados sob o foco de reflexões e de crítica para que não percam seu valor essencial de bases e instrumentos do desenvolvimento humano integral.

Neste sentido, a docência universitária tem responsabilidades múltiplas e implicações variadas. Recordemos Paulo Freire (1998) quando nos conclama à reflexão sobre as exigências da docência, aos seus saberes fundamentais. Como seres humanos inconclusos, como docentes, necessitamos de estar permanentemente inseridos num movimento de procura, de redescoberta, na intenção de se superar a curiosidade ingênua para a crítica e epistemológica.

Assim, a docência universitária exige a compreensão de que "não há docência sem discência". E aqui se coloca a questão: o que significa ensinar; o que compreende por aprender; qual o papel do professor e do aluno neste processo? Parte-se do pressuposto de que o ensinar implica que os alunos aprendam, que todos aprendam num processo construtivo do conhecimento que ultrapasse os limites mínimos da memorização para 
alcançar patamares mais elevados de compreensão, análise, síntese, problematização, criticidade, contextualização, avaliação e aplicação.

Precisamos, então, de professores capazes de empreender tal tarefa com êxito. Mas, esta é uma questão que nos leva a algumas reflexões, dentre elas a de que os professores universitários aprendem a ensinar ensinando. É pela experiência cotidiana, pelo exercício profissional na sua área específica do conhecimento que vão se construindo professores.

Um outro ponto colocado por Paulo Freire (1998) é o de que "ensinar não é transferir conhecimento", a competência vai além, do repasse mecânico de conteúdos. Dimensões científicas, políticas, éticas, estéticas e técnicas conferem a dimensão social comprometida com as melhoras da sociedade. É preciso que se tenha clareza de que neste processo de ensinar e aprender, "vá ficando cada vez mais claro que, embora diferentes entre si, quem forma se forma e re-forma ao formar e quem é formado forma e forma-se no ser formado." (FREIRE, 1998, p. 25). Em outras palavras, há a recusa do autor pelo "ensino bancário", pelo depósito mecânico do saber, pela inculcação sistematizada do conhecimento, numa direção vertical entre quem tudo sabe e o que ignora tudo. Na opinião do autor

Quando vivemos a autenticidade exigida pela prática de ensinar-aprender participamos de uma experiência total, diretiva, política, ideológica, gnosiológica, pedagógica, estética e ética, em que a boniteza dever acharse de mãos dadas com a decência e com a seriedade. (FREIRE, 1998, p. 26).

Por último, Freire nos chama a atenção para o fato de que "ensinar é uma especificidade humana". A docência exige um elevado nível de segurança do professor, expressa pela forma como assume o seu trabalho, como toma decisões, como se respeita e respeita o outro. Ser professor exige também competência profissional, aqui entendida não como o domínio de um corolário de técnicas pedagógicas ou domínio de um saber específico. Precisamos ir mais além. É necessário se colocar numa posição que permita a análise crítica contínua da prática pedagógica, dos saberes que vão sendo construídos, aprofundando essa crítica reflexiva assentada num seguro campo teórico da educação e do ensino.

Isto significa reconhecer que a docência faz parte de um campo do conhecimento específico:

a)Conteúdos das diversas áreas do saber e do ensino, ou seja, das ciências humanas e naturais, da cultura e das artes; b) conteúdos didáticopedagógicos, diretamente relacionados ao campo da prática profissional; c) conteúdos relacionados a saberes pedagógicos mais amplos do campo teórico da prática educacional; d) conteúdos ligados à explicação do sentido da existência humana individual, com sensibilidade pessoal e social. (PIMENTA, 2009, p. 49).

Nóvoa (2009) ao tratar deste tema coloca-se na posição de voltar seu olhar preferencialmente para os elos que se estabelecem entre as dimensões pessoais e profissionais.

Coloco, assim, a tônica numa (pré) disposição que não é natural mas construída, na definição pública de uma posição com forte sentido cultural, numa profissionalidade docente que não pode deixar de se construir no interior de uma pessoalidade do professor. (p. 30) 
Neste caso, considera elementos essenciais à docência o conhecimento que se deve ter para que os alunos aprendam. Este deve estar interligado à cultura profissional que vai adquirindo pelo exercício da prática, pela reflexão que dela resulta. Para tal é necessário que o professor tenha "tato", ou seja , ser capaz de administrar com bom senso os desafios que se lhe põe. Faz também parte de sua "competência ter a capacidade para trabalhar em equipe, organizando-se intra e extra instituição, demonstrando o seu compromisso social.

\section{PERCORRENDO TRILHAS METODOLÓGICAS}

Elegemos para esta pesquisa a abordagem qualitativa, compreendendo-a como " $a$ escolha correta de métodos e teorias oportunos, no reconhecimento e análise de diferentes perspectivas, nas reflexões dos pesquisadores a respeito de sua pesquisa como parte de um processo de produção do conhecimento, e na variedade de abordagens e métodos" (FLICK, 2004, p. 20). Neste caso, o objeto do estudo - "histórias de vida de professores aposentados"- foi fator determinante para a escolha do método.

Direcionamos nosso olhar e o nosso fazer para a consecução dos seguintes objetivos:

1. Registrar versões alternativas de construção da identidade docente

2. Possibilitar a construção de evidências pelo entrecruzamento de depoimentos

3. Analisar como os professores percebem as situações concretas de seu percurso educativo

4. Construir um suporte discursivo para compreender a história da educação no Pará, a partir da captura de narrativas de professores aposentados no ICED/UFPA, acerca da constituição de sua identidade profissional, cultural e simbólica, que remete à história - quase invisível, de um tempo/lugar específico, no norte brasileiro.

A opção pelo método autobiográfico instigou-nos a enfrentamentos básicos, dentre eles, a quantidade de sujeitos envolvidos para tornar "verdadeiros" nossos achados. Decidimos trabalhar com professores que se dispusessem a colaborar, aceitando nossa proposta. Foram realizadas 12 entrevistas. Em se tratando das narrativas escritas, em alguns casos, as informações foram complementadas com entrevistas orais. Então, é preciso que se declare que este estudo não revela verdades imutáveis, indiscutíveis, definidas. É uma possibilidade, e como tal, estará sempre em processo de se refazer e reformular.

Ao tratar de suas possibilidades como fonte de pesquisa Queiroz (1988) e Bom Meihy (1996) consideram que este método autobiográfico está inserido numa abordagem predominantemente qualitativa, voltada para a compreensão do presente, possibilitando ao mesmo tempo, a compreensão do passado pela voz dos sujeitos envolvidos. Este procedimento possibilita verificar a importância atribuída pelos narradores aos acontecimentos, abrindo, não raras vezes a porta a novos significados; uma vez que contribui para o entendimento das representações e da interpretação dadas aos diferentes acontecimentos da vida cotidiana do sujeito.

Ao se fazer a opção pelo resgate das histórias de professores elegemos como referencial teórico metodológico os princípios que configuram as narrativas (orais e/ou escritas). Na narrativa retrospectiva de experiências são relatados eventos da história de vida pela forma como foram vivenciados pelo narrador enquanto ator. Com as narrações, comunicamos as representações das ações realizadas, enquanto memórias e não como 
cópia exata da realidade. São manifestações do pensamento, permitindo representar, examinar, reelaborar, comunicar e projetar a ação.

As narrativas colocam-se desta forma na tradição dos estudos etnográficos que entroncam num campo teórico pluriparadigmático, quer no que se refere aos pressupostos teóricos, quer quanto aos pressupostos metodológicos. No caso desta pesquisa, as narrativas constituem-se numa opção, dentro do leque de opções possíveis e têm a ver com a natureza do problema a ser estudado - a construção da identidade dos professores universitários.

Pela narrativa recorremos à memória dos sujeitos. Como declara Delgado (2006, p.9) "a memória é uma construção sobre o passado, atualizada e renovada no tempo presente." Para Chauí (1995, p. 125) "A memória é uma evocação do passado. É a capacidade humana de reter e guardar o tempo que se foi, salvando-o da perda total'.Portanto, tempo e memória configuram-se como elementos de um único processo. Constituem-se em pontes de ligação que integram as múltiplas extensões da temporalidade em movimento.

É aqui que a memória se constitui em peça fundamental dessa dinâmica como a grande revitalizadora do existir. No entanto, o voltar à memória não significa estabelecer uma rigidez entre passado, presente e futuro. Memória e tempo estão intimamente ligados e podem ser analisados através do resgate da história de vidas ou dos relatos de vida.

O material coletado, expresso em textos, representa uma fonte riquíssima de informações. O procedimento de análise destas informações foi pautado pela análise de conteúdo inspirada no que propõe Bardin (1977) e Franco (2005). Entre as autoras existe a compreensão de que a análise de conteúdo, instrumento de análise interpretativa é uma das técnicas de pesquisa mais antiga, pois, como se sabe, a atitude interpretativa faz parte do ser humano que deseja atingir o conhecimento.

Não definimos categorias $a$ priori. O texto está nos revelando os caminhos a seguir e as categorias estão fluindo naturalmente. Evitamos, desta forma, o que comumente se denomina de "camisa de força", quando se buscam elementos para se encaixar no que foi previamente determinado.

Desta forma, o olhar do homem no tempo e através do tempo revela uma forte marca de historicidade. São os homens que constroem sua visão e representação das diferentes temporalidades e acontecimentos que marcaram sua própria história. Tempo, memória, espaço e história estão entrelaçados e caminham juntos. (DELGADO, 2006, p. $34)$.

As possibilidades abertas pelo resgate da memória possibilitou articular biografia e história, na percepção de como o individual e o social estão conectados. Permitiu ir além dos registros feitos por quem "olha do alto". Sinalizou, também para o que está ocultado, encoberto e mascarado, necessitando ser recuperado e libertado do seu silêncio. Possibilitou-nos entender o presente a partir do passado e o futuro não como um determinismo, mas como resultado de uma construção contínua, como declara Galeano (1994, p.96) "Para os navegantes com desejo de vento, a memória é um porto de partida". Voltar ao passado é viver um encontro com o que fomos e o que hoje somos.

\section{PARA FINALIZAR}

Participar desta pesquisa voltada para a memória de professores aposentados, pareceu-nos, desde o início, como uma tarefa instigante e fascinante, tanto pela temática que trata de como o professor se faz, quer pela nova incursão metodológica que o grupo 
vem enfrentado ao se envolver com memórias autobiográficas narrativas. Como diz Bosi (2006, p. 399)

Quanto mais a memória revive o trabalho que se faz com paixão, tanto mais se empenha o memoralista em transmitir ao confidente os segredos do ofício... Aquilo que se viu e se conheceu bem, aquilo que custou anos de aprendizado e que, afinal, sustentou uma existência passa (ou deveria passar) à outra geração como valor... A memória do trabalho é o sentido, é a justificação de toda uma biografia.

Não raro encontramos obras que tratam do tema, discutindo e analisando o fazer do professor "do lado de fora". Aqui damos vez e voz aos professores. Vozes e histórias silenciadas, mas legítimas e autênticas. Eles são os sujeitos, pessoas que nos relatam suas experiências às vezes comuns, mas também impregnadas de singularidades, refutando-se a idéia de homogeneização e acatando o princípio da pluralidade e da diversidade que os caracterizam.

Cada professor tem uma história, uma maneira própria de sentir-se no mundo. Os textos narrativos estão revelando situações vivenciadas ao longo de suas caminhadas pela carreira do magistério. São como nos fala Vasconcelos (2000, p. 8) "pedaços de suas vidas, com suas histórias há muito guardadas". São pessoas possuidoras de sonhos, desejos, projetos, frustrações, utopias e, como tantas outras, dispostas a partilhar suas lembranças quando encontram ouvidos atentos que mostram interesse em conhecê-las.

A possibilidade aberta pelo resgate da memória, mediante as histórias de vida, está possibilitando articular biografia e história, na percepção de como o individual e o social estão conectados. Permite ir além dos registros feitos por quem "olha do alto". Sinaliza, também, para o que está ocultado, encoberto e mascarado, necessitando ser recuperado e libertado do seu silêncio. Possibilita-nos entender o presente a partir do passado e o futuro não como um determinismo, mas como resultado de uma construção contínua, como declara Galeano (1994, p.96) "Para os navegantes com desejo de vento, a memória é um porto de partida".

Voltar ao passado é viver um encontro com o que fomos e o que hoje somos. Acreditamos que na continuidade deste trabalho possamos trazer toda a riqueza do que está expresso nos textos, até o presente momento evidenciado pelos procedimentos da préanálise.

Um olhar inicial sobre as informações coletadas revelaram que as histórias vão se entrelaçando. Histórias individuais refletem histórias coletivas, que micro-histórias trazem macro-histórias Cada história narrada contém informações do todo sócio-histórico-cultural do contexto. Histórias que se tangenciam e vão dando o tom, algumas vezes semelhantes; outras com nuances, diferenciadas, singulares.

Mais detalhadamente, concluímos que:

1. na trama das relações sociais de seu tempo, os indivíduos que se fazem professores vão se apropriando das vivências práticas e intelectuais, de valores éticos e das normas que regem o cotidiano educativo e as relações no interior e no exterior do corpo docente. Nesse processo, vão constituindo seu "ser profissional", na adesão a um projeto histórico de escolarização. Somente o distanciamento da experiência imediata e o confronto com outras perspectivas emergentes na prática sociais tornam possível a esse indivíduo perceber-se no contexto em que se foi constituído professor, analisar a emergência, a articulação e a superação das muitas vozes e das categorias por elas produzidas, para significar os processos culturais, e então criticar-se (ou não) e rever-se (ou não), aderindo (ou não) a um outro projeto de escolarização; 
2. procurar nos relatos, retomar recordações e experiências, expressar idéias e opiniões geraram uma série de dimensões de análises que surgem desse procedimento de construção dialética de dados: as contribuições mais significativas para a sua formação, as experiências mais valiosas para a sua formação enquanto docente. Neste sentido trazer à tona a história de professores aposentados permite que eles se apresentem como portadores de uma identidade profissional. Diante disso as narrativas autobiográficas (orais e escritas) revelaram o magistério como parte significativa da experiência e da identidade destes sujeitos, contudo é importante salientar que eles não são só o magistério. São pessoas concretas, plurais que se fazem historicamente a partir do contexto social onde vivem suas experiências cotidianas. É nesse sentido que buscamos resgatar nas narrativas autobiográficas dos professores aposentados, para refletir sobre os relatos de vivências de certos acontecimentos, dar nova forma aos sentimentos, pois são as práticas que compõem o nosso fazer hoje;

3. a formação dos professores dá-se num processo de construção inicial e formação continuada. O professor universitário vai se formando na continuidade de seu exercício profissional, uma vez que não há uma formação específica para tal. Requer-se aqui seu acumulo de experiências como aluno, ou como docente em outros níveis e modalidades de ensino. Podemos até dizer que sua formação caracteriza-se pelo autodidatismo;

4. a sua "identidade" é epistemológica, pois considera a docência como um campo do conhecimento específico. Percebemos que a maioria dos professores tiveram sua formação marcada pelo modelo jesuítico. Foram desafiados a realizar um trabalho de superação desse modelo, o que requereu um posicionamento de abertura e flexibilidade para enfrentarem os desafios educacionais que se colocavam presentes no exercício cotidiano da docência;

5. num processo de formação profissional para o exercício da docência superior, foram aproveitando as oportunidades educativas possíveis à realidade que os circunscreveu marcada pelo isolamento espacial e distanciamento dos centros mais avançados do país. Nota-se a dificuldade para se deslocarem para a realização de um programa de pós-graduação Implicações de ordem familiar e econômica retiveram a maior parte dos professores aqui em Belém, àquela altura em que a UFPA oferecia somente cursos de Especialização. Foram desbravadores e muito corajosos os primeiros professores que saíram para cursar o mestrado (momento em que há a oportunidade de sistematização e desenvolvimento de habilidades para pesquisar);

6. talvez, este tenha sido um forte indicador para justificar a timidez de desenvolvimento de projetos e pesquisa, esta considerada como uma prática individual e coletiva que viabiliza a construção de um pensar consciente sobre nossas certezas e incertezas. Vale ressaltar a importância da criação do Serviço de Planificação e Pesquisa (SPE) como alavancador de uma política de investigação na área de educação, destacando-se aqui a questão regional;

7. quanto à extensão, também observamos um número exíguo de projetos. Analisando a distribuição da carga horária pelas atividades fins da Universidade, é visível a superioridade numérica destinada ao ensino da graduação, seguindo-se o exercício de atividades administrativas;

8. vale destacar a política de interiorização da Universidade na Região Norte com um programa bem definido para interiorizar a formação de recursos humanos para a 
educação. Este programa atingiu diversos municípios do Estado do Pará e os então territórios de Roraima, Rondônia e Amapá. Houve uma grande participação dos professores nesse projeto, uma vez as aulas eram ministradas em períodos de recesso. Portanto, a contribuição de nosso professores foi altamente significativa para o desenvolvimento regional na área da educação.

9. sua formação para a docência superior deu-se mais por um processo intuitivo e autodidata- aprenderam a ensinar ensinando, com alguns exemplos claros de seguirem o exemplo mediante o convívio com outros professores (ensaios da profissão . As dúvidas do "que ensinar" e do "como ensinar" eram resolvidas mediante o processo de construção a própria profissionalidade docente superior. Então, entendemos que a formação dá-se não apenas nos cursos (formação inicial), mas também no exercício profissional (formação continuada), o que significa considerar o conceito de desenvolvimento profissional envolvendo as duas formas, num processo construção continuada.

10. muitos professores se viram compelidos a se aposentar muito cedo em razão da instabilidade econômica e como forma de preservar direitos trabalhistas. A maioria encontrava-se no auge de suas carreiras profissionais no momento da aposentadoria, o que as fez continuar exercendo a profissão em outros espaços institucionais.

As trajetórias profissionais relatadas revelam percursos distintos, mas pontos em comuns no que diz respeito a fatos marcantes da construção da história do curso de pedagogia da UFPA. Os relatos foram marcados pela afetividade, seriedade, compromisso em todas as falas. As marcas individuais se entrelaçaram com histórias coletivas que ao serem narradas nos ajudam recompor identidades pessoais e profissionais tecidas entre tensões e harmonias, entre contradições e ambigüidades, mas acima de tudo como modos de vida singulares. Recontá-las nos possibilitou adentra em vias labirínticas, recuperar o passado e construir novas perspectivas futuras.

Entendemos que o esforço por ouvir e por dar voz a esses professores, é o reconhecimento de que essas trajetórias são importantíssimas na construção da identidade docente no ensino superior. Hoje aposentados, falam-nos sobre a construção de sua identidade profissional, historicamente construída no seio do contexto social lócus da sua vivência cotidiana. Suas narrativas estão impregnadas pelas vivências, seus sonhos, realizados ou não, revelando-se dispostos a partilhar suas lembranças, considerando que o resgate da memória, articulando biografia e história possa, contribuir para em se conhecendo melhor o passado, melhor se compreenda o presente e se pense no futuro com a alma mais aberta e mais livre de amarras.

\section{REFERENNCIAS}

BARDIN, Laurence. Análise de conteúdo. Lisboa: Edições 70, 1977.

BENJAMIN, Walter. Magia e técnica, arte e política. In: Obras escolhidas. São Paulo: Brasiliense, 1987.

BOM MEIHY, José Carlos Sebe. (Re) introduzindo história oral no Brasil São Paulo: Xamã, 1996.

BOSI, Ecléa, Memória e sociedade: lembranças de velhos. São Paulo: Companhia das Letras, 2006. 
CHAUÍ, Marilena. Convite à Filosofia. São Paulo: Ática, 1995.

CUNHA, Maria I. O professor universitário na transição de paradigmas. Araraquara: JM, 1998.

DELGADO, Lucila. História oral: memória, tempo, identidades. Belo Horizonte: Autêntica, 2006.

FLICK, Uwe. Uma introdução à pesquisa qualitativa. Porto Alegre: Bookman, 2004.

FRANCO, Laura Maria Puglisi Barbosa. Análise de conteúdo.Brasília: Líber Livro Editora, 2005.

FREIRE, Paulo. Pedagogia da autonomia: saberes necessários à prática educativa. São Paulo: Paz e Terra, 1998.

GALEANO, Eduardo. As palavras andantes. Porto Alegre: L\&PM, 1994.

GOODSON, Ivor E. Dar voz ao professor; as histórias de vida dos professores e seu desenvolvimento profissional. In: NÓVOA A. (Org.) Vidas de professores. Porto: Porto Editora, 1992, p. 63-78.

NEVES, Lucilia de Almeida. Jardim do tempo. Belo Horizonte: Del Rey, 1999.

NÓVOA, António. Professores imagens do futuro presente. Lisboa: EDUCA, 2009.

NÓVOA, A. (Org.) Profissão professor. Porto: Porto Editora, 1992.

PIMENTA, Selma G. e ANASTASIOU, Lea das Graças. Docência no ensino superior. Vol 1. São Paulo: Cortez, 2002.

QUEIRÓZ, Maria Isaura Pereira de. Relatos orais: do "indizível" ao "dizível". In: SIMSOM, Olga de Marques Von. (Org.). Experimentos com história de vida.São Paulo: Vértice/Revista dos Tribunais, 1988, p. 14-43.

SARMENTO, Manuel J. A vez e a voz dos professores. Porto: Porto Editora, 1994.

THOMPSON, Paul. A voz do passado. Rio de Janeiro: Paz e Terra, 2002.

VASCONCELOS, Geni A. Nader. Puxando um fio... In: VASCONCELOS, Geni (org.) Como me fiz professora. Rio de Janeiro: DP e A Editora, 2000, p. 7-19.

Recebido em: 01/09/2011

Aprovado em: 15/09/2011 